\title{
Kinetics and equilibrium studies of the adsorption of nickel (II) ions from aqueous solution onto modified natural and synthetic iron oxide
}

\author{
Kouoh Sone Paul-Michel Adolphe ${ }^{1}$, Tagne Guy Merlain ${ }^{1}$, LekeneNgouateu René Blaise ${ }^{1}$, BelibiBelibi Placide \\ Desire $^{1}$, NdiNsami Julius ${ }^{1}$, Kouotou Daouda ${ }^{1}$, GhogomuNumbonui Julius ${ }^{2}$, \\ AnaghoGabche Solomon ${ }^{3}$, KetchaMbadcam Joseph ${ }^{1} *$ \\ ${ }^{I}$ Physical and Theoretical Chemistry Laboratory, Department of Inorganic Chemistry, Faculty of Science, \\ University of Yaoundé I, Yaoundé - Cameroon \\ ${ }^{2}$ Laboratory of Noxious Chemistry and Environmental Engineering, Department of Chemistry, Faculty of Science, \\ University of Dschang, Dschang - Cameroon \\ ${ }^{3}$ Department of Chemistry, Faculty of Science, University of Bamenda, Bamenda - Cameroon \\ *Corresponding author E-mail:jketcha@yahoo.com
}

Copyright $\odot 2015$ KetchaMbadcam Joseph et al. This is an open access article distributed under the Creative Commons Attribution License, which permits unrestricted use, distribution, and reproduction in any medium, provided the original work is properly cited.

\begin{abstract}
The present paper reports on the kinetic and equilibrium studies of the adsorption of Nickel(II) ions from aqueous solution onto modified natural iron oxide (NAT) from Mbalam (East Region of Cameroon) and synthetic iron oxide (SYNTH). The parameters investigated using batch techniques include, the contact time, adsorbent mass, $\mathrm{pH}$ and initial metal ion concentration. The experimental results obtained showed that, the optimum $\mathrm{pH}$ of 6 for bothadsorbents with an equilibrium time of 30 minutes was sufficient. The kinetic data correlated well with the pseudo-first-order and pseudo-second-order kinetic models for both the adsorbents based on the correlation coefficients $\left(\mathrm{R}^{2}\right)$ obtained. The adsorption processes followed both the Langmuir and the Tempkin adsorption models for the natural iron oxide, whereas the Freundlich and Tempkin adsorption models fitted well the adsorption data for the synthetic iron oxide. The maximum quantity of Nickel(II) ions adsorbed was $250 \mathrm{mg} / \mathrm{g}$ for the two adsorbents. These results revealed a high adsorption capacity of natural iron oxide which is comparable to that of synthetic iron oxide.
\end{abstract}

Keywords:Adsorption; Iron Oxide; Synthetic Iron Oxide; Isotherm Model; Kinetic Models; Nickel(II) Ions.

\section{Introduction}

Water pollution due to toxic heavy metals remains a serious environmental concern. Although, these heavy metals are at times essential to plants [1], they might at high dose become hazardous for animals and human beings [2]. Hence, heavy metals like zinc, copper, mercury, chromium and nickel are recognized to be toxic and non-degradable at high concentration [3]. Principally, nickel is a common pollutant arising from industries such as electroplating, metal processing and paints formulation [4]. According to the World Health Organisation, the tolerant limit of $\mathrm{Ni}^{2+}$ ions in drinking water is $50 \mathrm{mg} / \mathrm{L}$ [5]. Up to that acceptance does, nickel poisoning causes cyanosis, cancers of lungs, nose and bone. Thus, it is necessary to remove them from industrial wastewater [6]. Several methods such as chemical precipitation, coagulation, ion exchange, and adsorption are generally used [7]. Furthermore, adsorption wasreported as an efficient and economic feasible option [7]. A number of adsorbent materials have been studied for their ability to remove nickel such as zeolite [8], activated carbons [9, 10] iron oxides [11]. Magnetic iron oxides are commonly used for their good adsorbance properties and applications in nanotechnology [11]. In addition, the easy separation of metal loaded magnetic adsorbent from solution can be achieved using an external magnetic field. But, owing to the high and expensive cost of the synthetic iron oxide, a low cost material rich in iron oxide, which is abundant and available in the locality of Mbalam in the East Region of Cameroon is used. The aim of this work is to show out the uptake of nickel(II) 
ions by treated iron oxide from Mbalam and synthetic iron oxide. Thus, the effect of contact time, amount of adsorbent and concentration of the adsorbate on the uptake of nickel(II) ions on adsorbents was thoroughly investigated from a kinetic and equilibrium point of view.

\section{Materials and methods}

\subsection{Adsorbent}

Natural iron oxide

The natural iron oxide from the locality of Mbalam in the East Region of Cameroon had as GPS coordinates: 0214100N and $01356926 \mathrm{E}$. In order to transform our adsorbents into magnetic particles, $10 \mathrm{mg}$ of NAT were used with $5 \mathrm{~mL}$ of aniline and $1 \mathrm{~mL}$ of sulfuric acid which was all mixed and heated up to $800^{\circ} \mathrm{C}$ in a carbolite furnace. The goal was to have at high temperature a partial reduction of iron(III) ions to iron(II) ions which confers magnetic properties. After cooling at room temperature, NAT was sieved using $80 \mu \mathrm{m}$ mesh sieve. The specific surface area was $3.97 \mathrm{~m}^{2} / \mathrm{g}$ from BET result.

Synthetic iron oxide

$8 \mathrm{~g}$ of iron(II) sulphate and $1 \mathrm{~g}$ of iron(III) chloride were dissolved in $200 \mathrm{~mL}$ of distilled water (co-precipitation method). $200 \mathrm{~mL}$ of $\mathrm{NH}_{4} \mathrm{OH}(25 \%)$ was added to the mixture at $100{ }^{\circ} \mathrm{C}$ for $1 \mathrm{hr}$. After drying, the particles were fractionated using a fraction finer of $80 \mu \mathrm{m}$.

These particles of $80 \mu \mathrm{m}$ of sizes were primarily heated in a carbolite furnace at $110{ }^{\circ} \mathrm{C}$ for 24 hours, cooled in a dessicator before the adsorption experiments.

\subsection{Adsorbate}

The synthetic effluent of (3000 mg/L) nickel(II) ions was prepared by dissolving the required amounts of nickel(II) chloride $(12,525 \mathrm{~g})$ in a conical flask of $(1000 \mathrm{~mL})$ and fill with distilled water. Different standard concentrations of nikel(II) ions were then prepared by dilution method.

\subsection{Characterization}

The synthetic iron oxide and the treated natural iron oxide were characterized using X-ray diffraction to know their crystallinity, the FT-IR spectroscopy to identify the functional groups and chemical bonding on the adsorbents and the BET method to have their surface area.

\subsection{Batch adsorption experiments}

The batch experiments for the adsorption studies were carried-out at room temperature in a $250 \mathrm{~mL}$ screw caped conical flask. For each run, 0.1 to $0.5 \mathrm{~g}$ of the adsorbent was introduced into the flask containing $20 \mathrm{~mL}$ of the nickel chloride solution at initial concentrations, $\mathrm{C}_{0}$ ranging from 1200 to $2000 \mathrm{~mL}$. After reaching the adsorption equilibrium, NAT and SYNTH were separated from the aqueous solution using simple filtration method. Then, the analysis of the residual solution was performed by UV-visible absorption spectrophotometry at $400 \mathrm{~nm}$ (UV-visible 259 Corning). The quantity adsorbed at equilibrium; Qe (mg.g $\left.{ }^{-1}\right)$ was calculated according to.

$\mathrm{Q}_{\mathrm{e}}=\frac{\left(C_{0}-C_{e}\right) V}{M}$

Where, $\mathrm{C}_{0}$ and $\mathrm{C}_{\mathrm{e}}$ (in $\mathrm{mg} \cdot \mathrm{L}^{-1}$ ) are the initial and equilibrium concentrations of nikel(II) in solution, respectively, $\mathrm{V}$ (in $\mathrm{L}$ ) is the total volume of the solution, and $\mathrm{M}$ (in $\mathrm{g}$ ) is the adsorbent mass.

The percentage removal of nikel(II) ions from solution was calculated by using the following equation:

$\%$ Removal $=\frac{\left(C_{0}-C_{t}\right)}{C_{0}} \times 100$

Where, $\mathrm{C}_{0}$ and $\mathrm{C}_{\mathrm{t}}\left(\mathrm{mg} . \mathrm{L}^{-1}\right)$ are the initial nickel(II) ions concentration and concentration at time t, respectively.

\subsection{Equilibrium isotherm}

Langmuir adsorption isotherm

The Langmuir adsorption isotherm is valid for monolayer adsorption onto a surface with a finite number of identical sites, which are homogeneously distributed over the adsorbent surface. It is generally expressed as [12]: 
$Q_{e}=Q_{m} \frac{K_{L} C_{e}}{1+K_{L} C_{e}}$

Where, $\mathrm{C}_{\mathrm{e}}$ is the equilibrium concentration of $\mathrm{Ni}^{2+}$ ion $(\mathrm{mg} / \mathrm{L}), \mathrm{Q}_{\mathrm{e}}$ is the amount of $\mathrm{Ni}^{2+}$ ions adsorbed per unit mass of the adsorbent; $\mathrm{KL}$ is the Langmuir adsorption constant $(\mathrm{L} / \mathrm{mg}), \mathrm{Q}_{\mathrm{m}}$ is the maximum amount of adsorbate per unit mass of adsorbent to form a complete monolayer on the surface $\left(\mathrm{mg} . \mathrm{L}^{-1}\right)$. The linear form of Langmuir equation is as follows:

$\frac{1}{Q_{e}}=\frac{1}{Q_{m} K_{L} C_{e}}+\frac{1}{Q_{m}}$

Freundlich adsorption isotherm

The Freundlich equation is an empirical equation based on the adsorption on a heterogeneous surface. Its general expression as [13]:

$\mathrm{Q}_{\mathrm{e}}=\mathrm{K}_{\mathrm{f}} \mathrm{C}_{\mathrm{e}}{ }^{1 / n}$

Where, $\mathrm{K}_{\mathrm{f}}$ and $\mathrm{n}$ are the Freundlich constants related to sorption capacity and sorption intensity of the adsorbent respectively. The linear form of this equation is:

$\ln \mathrm{Q}_{\mathrm{e}}=\ln \mathrm{K}_{\mathrm{f}}+(1 / \mathrm{n}) \ln \mathrm{C}_{\mathrm{e}}$

Dubinin-Kaganer-Radushkevich (D-K-R) model

Langmuir and Freundlich isotherms are insufficient to explain the physical and chemical characteristics of adsorption [14]. D-K-R is commonly used to describe sorption isotherm of single solute systems, and it is more general for nonhomogeneous surface. The D-K-R isotherm is expressed as [14]:

$\mathrm{Q}_{\mathrm{e}}=\mathrm{Q}_{\max } \exp \left[\frac{\left(\mathrm{RT} \ln \left(1+\frac{1}{\mathrm{C}_{\mathrm{e}}}\right)\right)^{2}}{-2 \mathrm{E}_{\mathrm{a}}^{2}}\right]$

$\mathrm{E}_{\mathrm{a}}$ is the main energy of adsorption and gives information about the physical and chemical features of adsorption. The linear form of the D-K-R isotherm equation is:

$\ln Q_{e}=\ln Q_{\max }-\beta \xi^{2}$

Where, $\xi=\mathrm{RT} \ln \left(1+1 / \mathrm{C}_{\mathrm{e}}\right)$ is called the Polanyi potential and R is the perfect gas constant $\left(\mathrm{J} \cdot \mathrm{K}^{-1} \cdot \mathrm{mol}^{-1}\right)$ and T $(\mathrm{K})$ the absolute temperature.

Tempkin Isotherm

The linear form of this isotherm is [15]:

$\mathrm{Q}_{\mathrm{e}}=\mathrm{B} \ln \mathrm{A}+\mathrm{B} \ln \mathrm{C}_{\mathrm{e}}$

Where,

A $(\mathrm{L} / \mathrm{g})$ is the Tempkin constant which gives maximum bond energy

$\mathrm{B}(\mathrm{J} / \mathrm{mol})$ is the Tempkin constant which gives adsorption heat

\subsection{Kinetic adsorption experiments}

The kinetic adsorption experiments were conducted using a series of $20 \mathrm{~mL}$ solutions containing $0.1 \mathrm{~g}$ of adsorbent and nickel ions concentration $(1600 \mathrm{~mL})$. The solutions were vigorously agitated with magnetic stirrer by increasing time intervals. Four kinetics models were used to fit our experimental data.

Pseudo-first order model

This model of Lagergren is generally expressed as follows [16]

$\frac{\mathrm{d} Q_{t}}{\mathrm{dt}}=\mathrm{k}_{1}\left(\mathrm{Q}_{\mathrm{e}}-\mathrm{Q}_{\mathrm{t}}\right)$

Where, $Q_{e}$ and $Q_{t}$ are the sorption capacity at equilibrium and at time, $t$, respectively (mg.g ${ }^{-1}$ ) and $k_{1}$ is the rate constant of the pseudo-first order sorption $\left(\mathrm{L} \cdot \mathrm{min}^{-1}\right)$. The integrated form is:

$\ln \left(\mathrm{Q}_{\mathrm{e}}-\mathrm{Q}_{\mathrm{t}}\right)=\ln \mathrm{Q}_{\mathrm{e}}-\mathrm{k}_{1} \mathrm{t}$

Pseudo-second order model 
If the rate of sorption is a second order mechanism, the pseudo-second order chemisorption kinetic rate equation is expressed as [17]:

$\frac{\mathrm{dQ}}{\mathrm{dt}}=\mathrm{k}_{2}\left(\mathrm{Q}_{\mathrm{e}}-\mathrm{Q}_{\mathrm{t}}\right)^{2}$

Where, $\mathrm{k}_{2}$ is the rate constant of pseudo-second order equation $\left(\mathrm{g} \cdot \mathrm{mg}^{-1}\right)$. The integrated and rearranged form equation is:

$\frac{\mathrm{t}}{\mathrm{Q}_{\mathrm{t}}}=\frac{1}{\mathrm{~K}_{2} \mathrm{Q}_{\mathrm{e}}^{2}}+\frac{1}{\mathrm{Q}_{\mathrm{e}}} t$

Intraparticle diffusion model

The linear form of this equation is expressed as follows [18]:

$\ln \mathrm{R}=\ln \mathrm{k}_{\mathrm{id}}+\alpha \ln \mathrm{t}$

Where, $\mathrm{R}$ is the percentage removal of nickel(II) ions at time $\mathrm{t}, \mathrm{k}_{\mathrm{id}}$ is the intraparticular diffusion rate constant and $\alpha$ is gradient whose value depends on the adsorption mechanism.

Elovich equation

The Elovich equation is generally expressed as follows [19]:

$\frac{\mathrm{dQ}_{\mathrm{t}}}{\mathrm{dt}}=\alpha \exp \left(-\beta \mathrm{Q}_{\mathrm{t}}\right)$

Where $\alpha$ is the initial sorption rate $\left(\mathrm{mg}^{-1} \cdot \mathrm{g} \cdot \mathrm{min}^{-1}\right), \beta$ is the desorption constant $(\mathrm{g} / \mathrm{mg})$ during any one experiment. The integrated and simplified equation:

$Q_{t}=\frac{1}{\beta} \ln (\alpha \beta)+\frac{1}{\beta} \ln t$

\section{Results and discussion}

\subsection{Characterization results}

FT- IR

The infrared spectrum was obtained using a Fourier transform-infrared spectrophotometer (alpha spectrophotometer IRTF Bruker) to identify the functional groups and chemical bonding of the cooled materials.Fourier infrared spectra (Figure 1) show the characteristics peaks of iron oxide for both adsorbents. For SYNTH and NAT, the peaks of Fe-O-Fe were found between $410-440 \mathrm{~cm}^{-1}$ and $580-610 \mathrm{~cm}^{-1}$ [20]. We have a broad band of $-\mathrm{OH}$ between $3000-3140 \mathrm{~cm}^{-1}$ which is allocated to water molecule on the synthetic material which doesn't exist or appear on NAT owing to the effect of calcination.

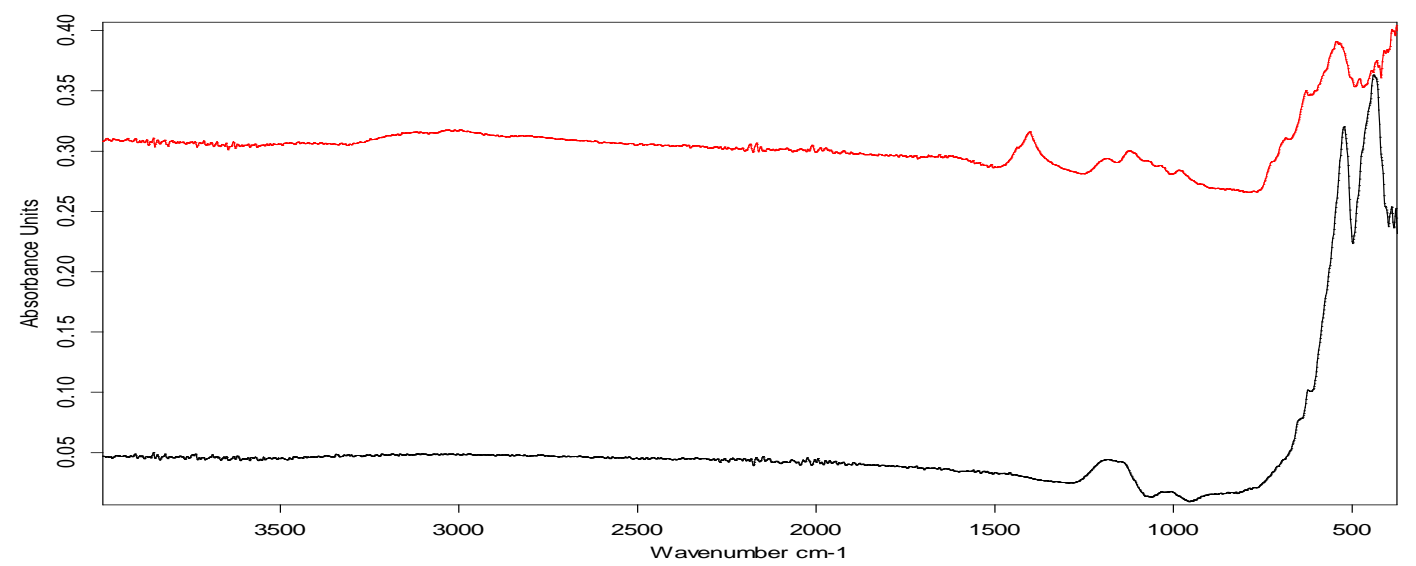

Fig. 1: Fourier Infrared Spectra of SYNTH (In Red) and NAT (In Black)

X-ray diffraction (XRD) Powder X-ray diffraction (XRD) patterns were used to identify the structure of adsorbents. For SYNTH, the Scherrer equation gave the values of $\mathrm{d}_{\mathrm{hkl}}$ with the peaks at $1.271 ; 1.381 ; 1.468 ; 1.796 ; 2.174 ; 2.366 ; 2.541$; $3.311 ; 4.129$ (Figure 2.(a)) which show good consistency with the reported data that can be indexed to a cubic 
maghemite-magnetite, but lattice parameter is very close to maghemite $\left(\gamma-\mathrm{Fe}_{2} \mathrm{O}_{3}\right)$ according with JCPDS file $\mathrm{N}^{\circ} 19$ 6629. Figure 2.b shows XRD patterns of NAT with the values of $d_{\text {hkl of }}$ $3.162 ; 2.308 ; 2.149 ; 1.894 ; 1.569 ; 1.454 ; 1.376 ; 1.276 ; 1.247$. This is a rhombohedric system characteristic of hematite $(\alpha-$ $\mathrm{Fe}_{2} \mathrm{O}_{3}$ ) which is the principal constituent of the material.The adsorbents showed magnetic properties which are important for the possibility of magnetic affinity with nickel which of course is paramagnetic.

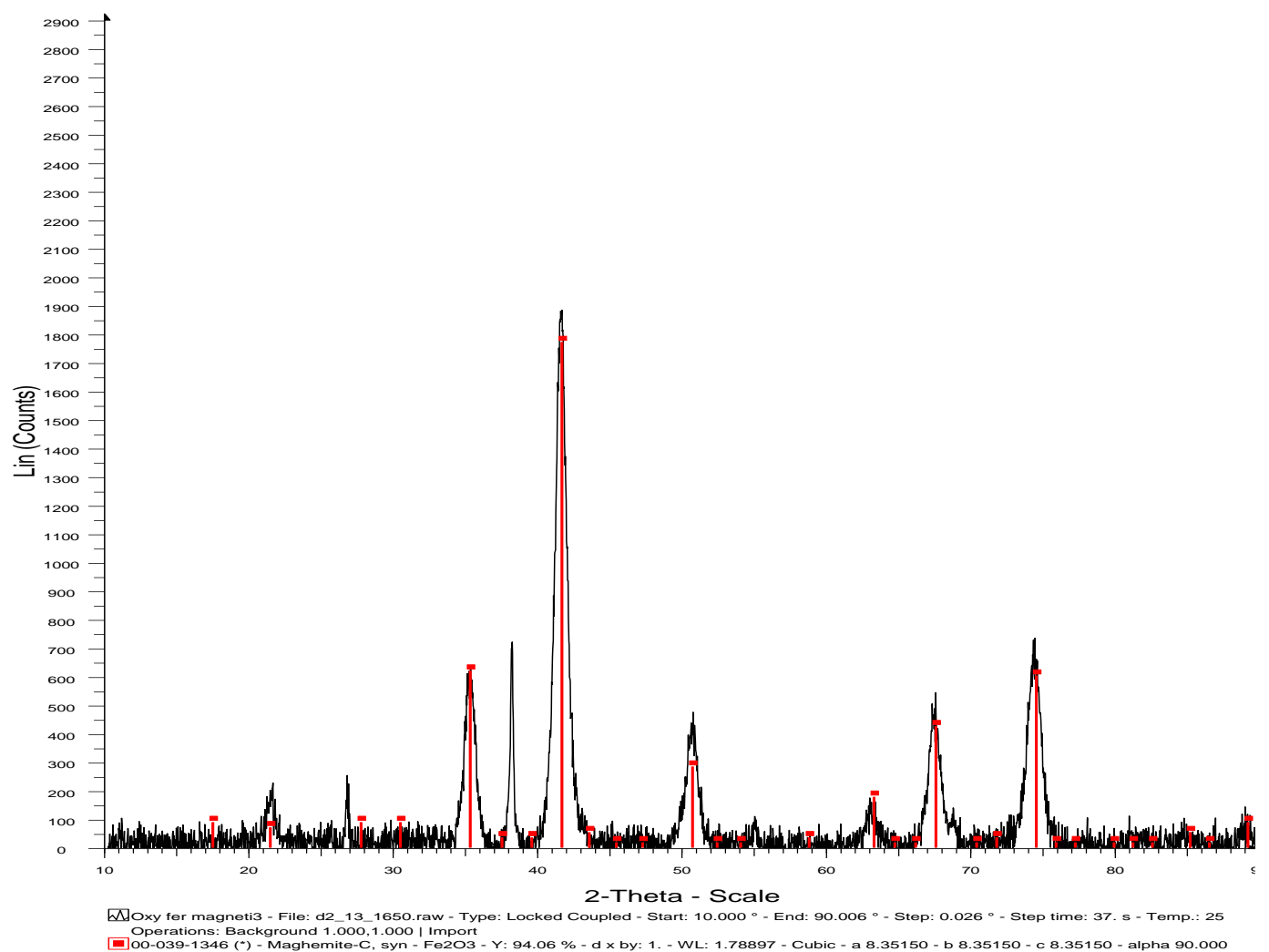

Fig. 2: A) XRD Patterns of SYNTH.

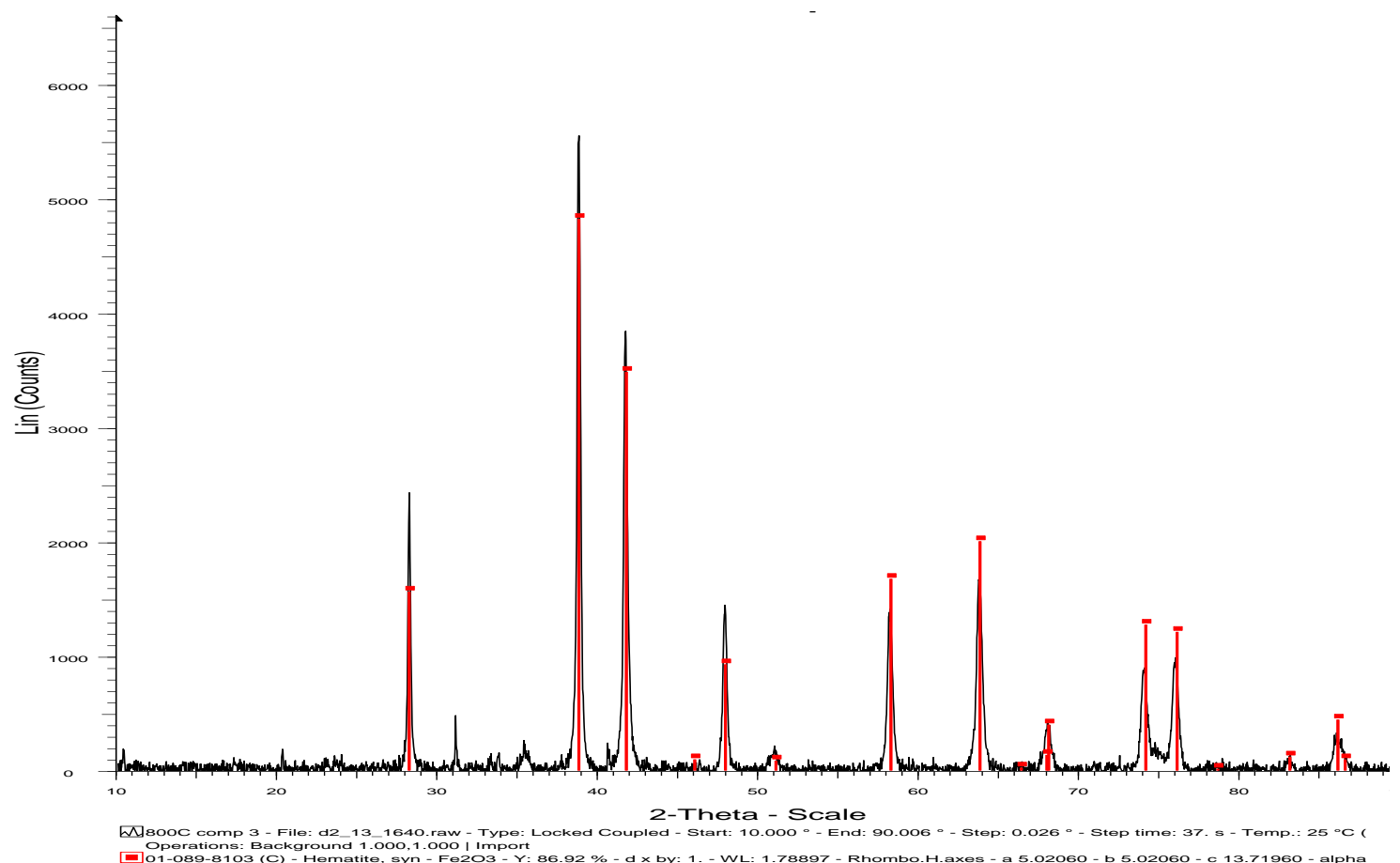

Fig. 2: B) XRD Patterns of NAT 
The analysis of the porosity is obtained by B.E.T method and the results are reported in Table 1. According to the IUPAC classification, we can observe that NAT is macroporous (diameter $>50 \mathrm{~nm}$ ) whereas SYNTH is mesoporous $(20<$ Diameter $<50 \mathrm{~nm})$.

Table 1: Porosity of Adsorbents

\begin{tabular}{ll}
\hline MATERIALS & PORE DIAMETER \\
\hline NAT & $60,11080 \mathrm{~nm}$ \\
SYNTH & $8,2288 \mathrm{~nm}$ \\
\hline
\end{tabular}

\subsection{Effect of contact time}

The adsorption data of the adsorbate on NAT and SYNTH versus the contact time at $1600 \mathrm{mg} / \mathrm{L}$ with $0.1 \mathrm{~g}$ of both the adsorbent are presented in Figure 3. The plot clearly shows two distinct regions for both the adsorbents. From 0 to 20 minutes for the NAT and SYNTH, the quantities of $\mathrm{Ni}^{2+}$ ions adsorbed increase rapidly. After that region, the adsorption kinetics slow down and gradually tends to level off. The adsorption reaches its maximum at 50 min with $122.5 \mathrm{mg} / \mathrm{g}$ for NAT and after $30 \mathrm{~min}$ with $120 \mathrm{mg} / \mathrm{g}$ for SYNTH. The adsorption increases rapidly because thereare more free active sites on the adsorbents, and then progressively, there is a saturation in the adsorbent sites which consequently, decrease adsorption kinetic. Similar case was recorded by previous work [10].

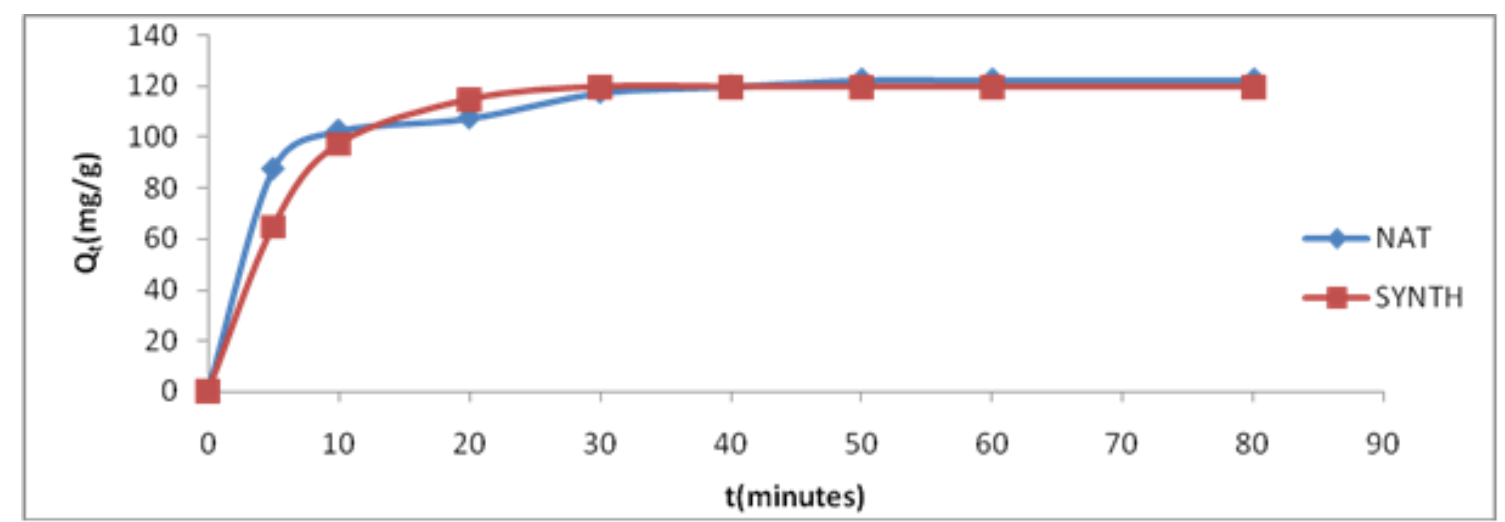

Fig. 3:Effect of the Agitation Time on the Adsorption of Nickel(II) Ions on the NAT and SYNTH

\subsection{Effect of the amount of adsorbent}

For this experiment, different masses of adsorbents were stirred with nickel(II) ions solution for 50 min using NAT and 30 min using SYNTH. The results are presented in Figure 4.a and 4.b. It is observed that nickel(II) ions adsorption percentage increases with adsorbent mass (Figure 4.a).This is because anincrease in the amount of mass increases the specific surface area of the adsorbents[21]. But, the adsorption capacity (mg/L) decrease with the amount of NAT and SYNTH (Figure 4.b). This is due to the agglomeration of the adsorbent particles which decrease diffusion path of adsorbate in adsorption sites [22].

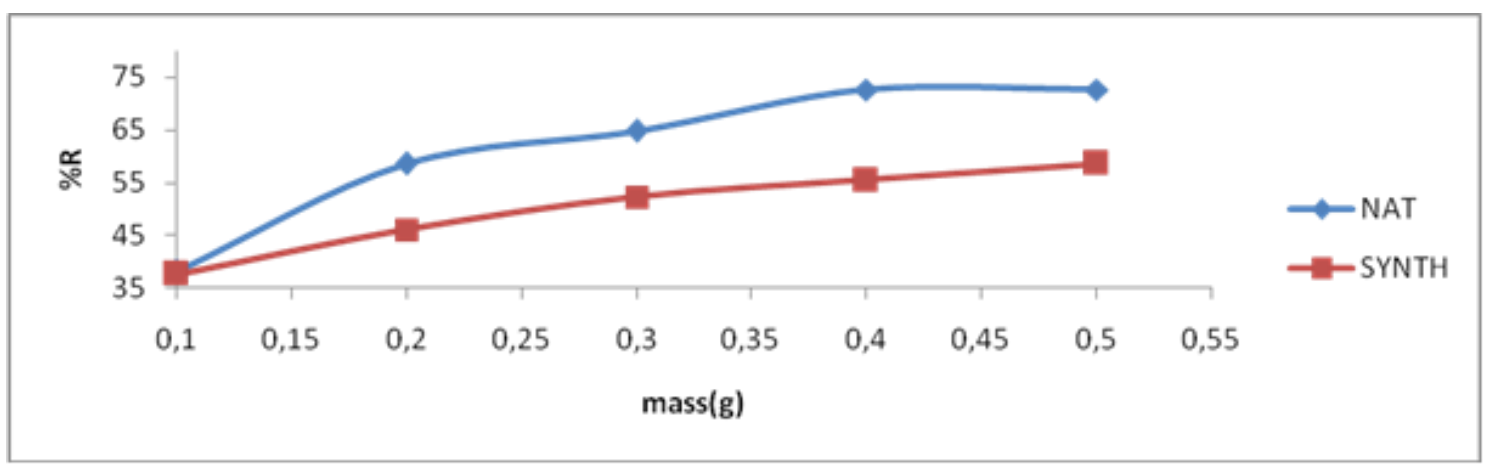

Fig. 4: A) Effect of the Adsorbent Mass on the Metal Ion Percentage 


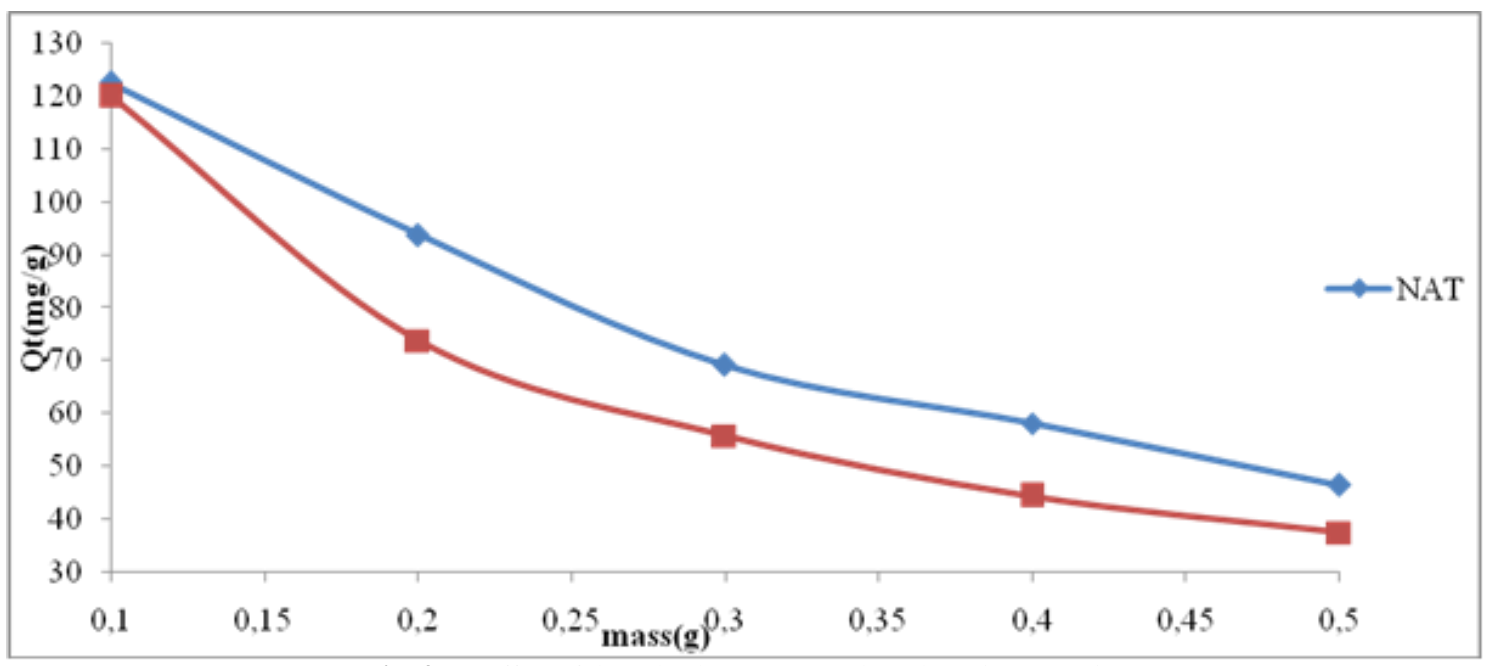

Fig. 4: B) Effect of the Adsorbent Mass on the Adsorption Capacity

\subsection{Effect of pH}

The effect of $\mathrm{pH}$ on the adsorption of nikel(II) ions on the NAT and SYNTH was studied at room temperature by varying the $\mathrm{pH}$ of nickel solution from $\mathrm{pH} 2$ to 8 (Figure5). From figure 5, it is observed that with an increase in $\mathrm{pH}$, the extent of adsorption increases and reaches a maximum value of $180 \mathrm{mg} / \mathrm{g}$ at $\mathrm{pH} 6$ for both the adsorbents [11]. However, the adsorption capacity decreases, if $\mathrm{pH}$ is further increased. At lower $\mathrm{pH}$, the adsorption capacity is weak due to the competition adsorption between $\mathrm{H}^{+}$ions and $\mathrm{Ni}^{2+}$ ions of the iron oxides surfaces. Whereas at $\mathrm{pH}$ higher than 6 , the nickel precipitate into the $\mathrm{Ni}(\mathrm{OH})_{2}$ which reduces the adsorbed quantity.

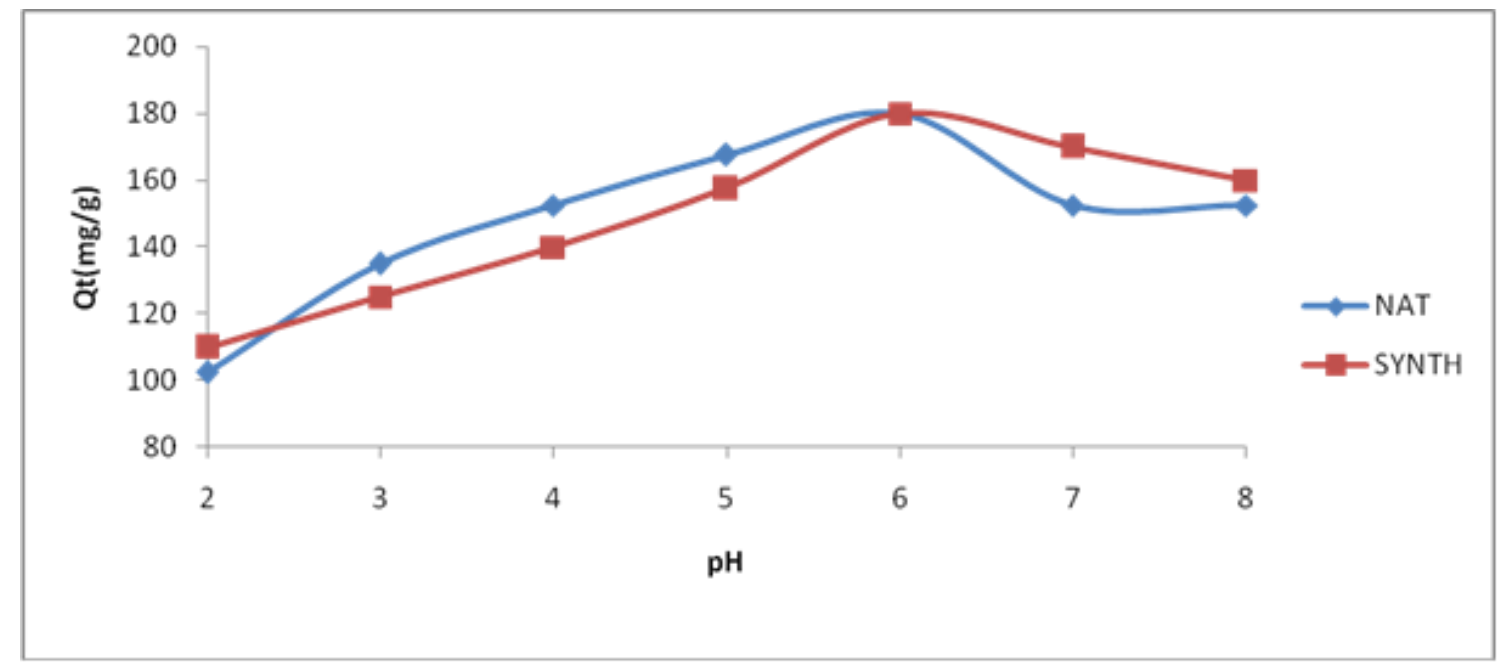

Fig. 5: Effect of the pH. on the Adsorption Capacity

\subsection{Adsorption isotherm}

The equilibrium studies were conducted with $0,1 \mathrm{~g}$ of both the adsorbents, NAT and SYNTH. These results are shown in Figure 6:

The adsorption isotherm seems to be of type IV, which is the characteristic of mesoporous adsorbent. The presence of two stages is due to the formation of two successive adsorbate layers on the surface. We have the type V for SYNTH, which is similar to type IV, and where the adsorbate-adsorbent bonds are very weak. The experimental data obtained from these studies have been tested with linearized equations of four isotherm models. These results are summarized in Table 2. According to these results, the adsorption isotherms are in agreement with the Langmuir and Tempkin models for the NAT, whereas the Freundlich and Tempkin models agree well for the SYNTH. The values of $1 / n$ are lower than 1 for both adsorbents, thus the adsorption surface are heterogeneous [23]. The experimental data follow the Tempkin model, and the adsorption energies are lower than $20 \mathrm{~kJ} / \mathrm{mol}$ which lead to multilayer formation on both adsorbents [24]. The correlation coefficients of Langmuir model suggest that, the interactions on the NAT surface are stronger than those on the SYNTH, which is in agreement with the isotherm of type V. Moreover, the $Q_{m}$ value is the same $\left(Q_{m}=250\right.$ $\mathrm{mg}$ ) for the NAT and SYNTH which of course have similar adsorption capacities. 


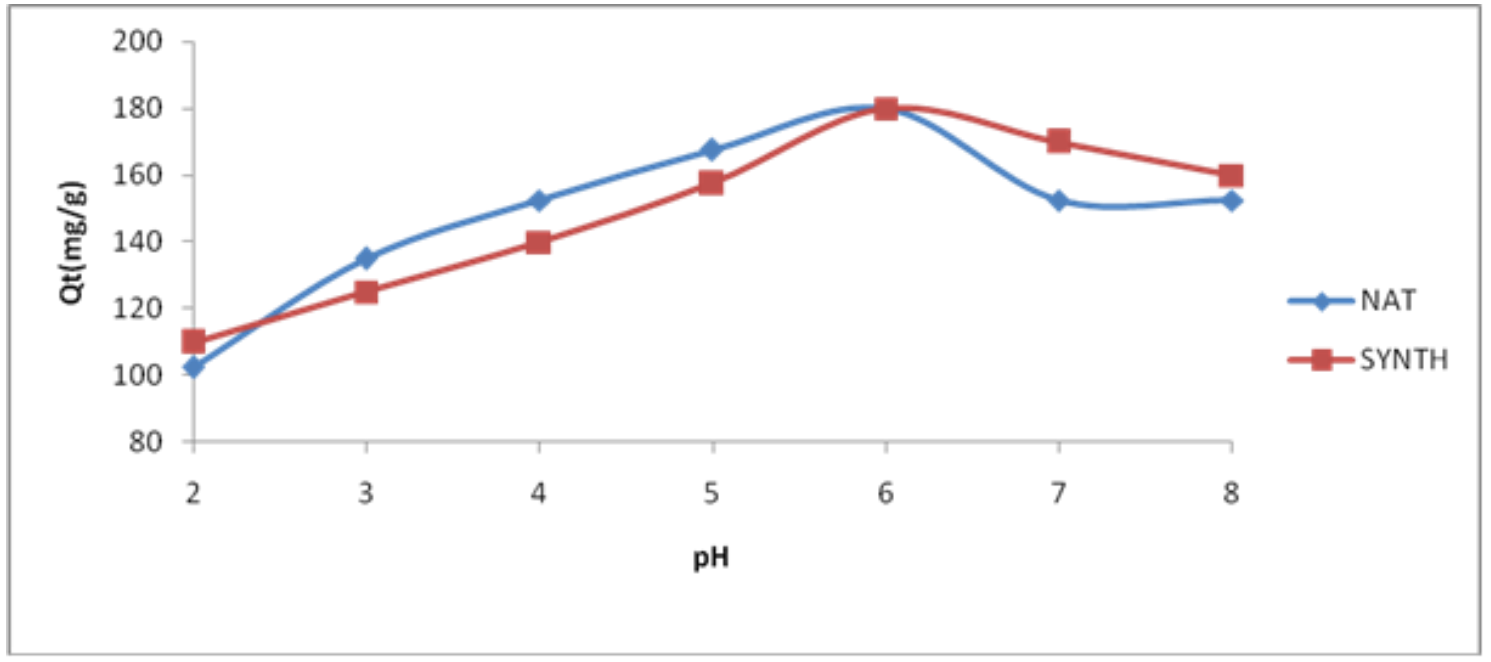

Fig. 6: Effect of the Concentration on Adsorption Capacity

Table 2: Isotherm Parameters for $\mathrm{Ni}^{2+}$ Ions Uptake from Aqueous Solutions

\begin{tabular}{|c|c|c|c|c|c|c|c|c|c|c|c|c|c|}
\hline Models & \multicolumn{3}{|c|}{ Langmuir } & \multicolumn{3}{|c|}{ Freundlich } & \multicolumn{4}{|l|}{ D-K-R } & \multicolumn{3}{|l|}{ Tempkin } \\
\hline Parameters & $\mathrm{K}_{\mathrm{L}}$ & $\mathrm{Q}_{\mathrm{m}}(\mathrm{mg} / \mathrm{g})$ & $\mathrm{R}^{2}$ & $\mathrm{~K}_{\mathrm{F}}$ & $1 / \mathrm{n}$ & $\mathrm{R}^{2}$ & $\mathrm{~K}^{\prime}$ & $\mathrm{Q}_{\mathrm{m}}(\mathrm{mg} / \mathrm{g})$ & $\mathrm{E}(\mathrm{kJ} / \mathrm{mol})$ & $\mathrm{R}^{2}$ & $\mathrm{~B}(\mathrm{~J} / \mathrm{mol})$ & $\mathrm{A}(\mathrm{l} / \mathrm{g})$ & $\mathrm{R}^{2}$ \\
\hline NAT & $\begin{array}{l}6.380 \\
\times 10^{-3}\end{array}$ & 250 & 0.96 & 56.21 & 0.174 & 0.956 & 0.005 & 190.757 & 10 & 0.916 & 30.32 & 0.487 & 0.958 \\
\hline SYNTH & $\begin{array}{l}6.957 \\
\times 10^{-3} \\
\end{array}$ & 250 & 0.966 & 59.50 & 0.168 & 0.979 & 0.004 & 191.205 & 11.180 & 0.905 & 29.59 & 0.611 & 0.978 \\
\hline
\end{tabular}

\subsection{Kinetic modeling of $\mathrm{Ni}^{2+}$ ions adsorption}

The adsorption kinetic of nickel(II) ions has been studied using four kinetic models. The experimental data have been tested with linear forms of these models. The straight line plots are presented in Figures 7 to 10 and the kinetics parameters are given in Table 3.

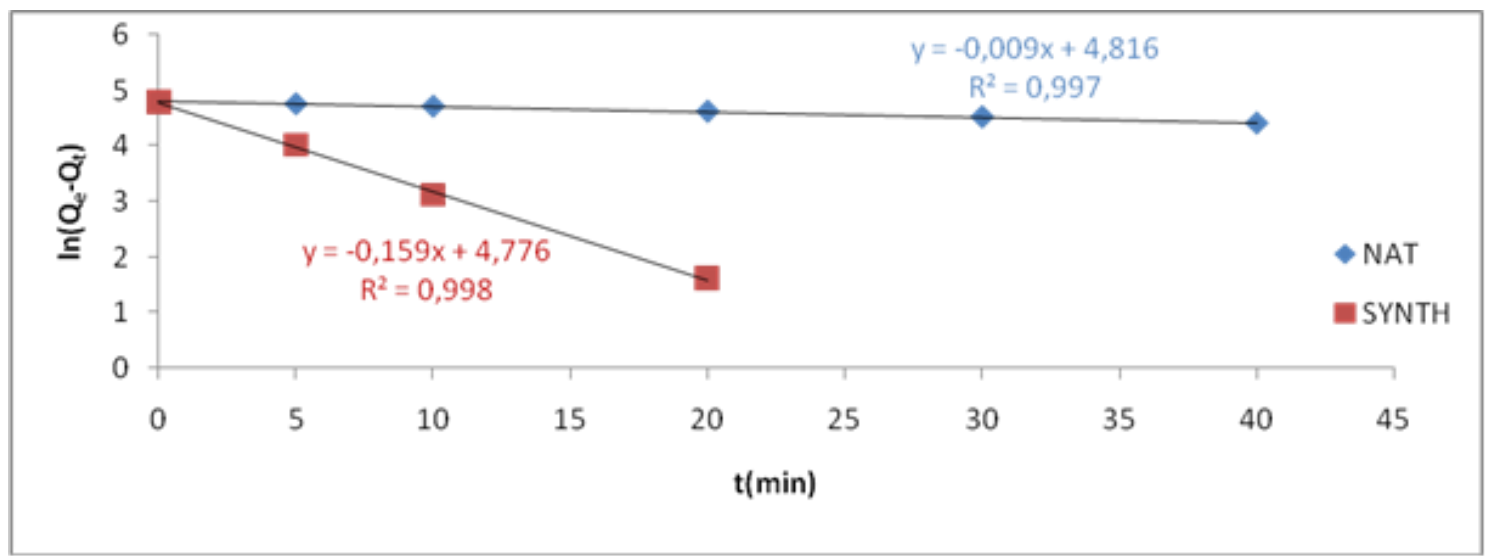

Fig. 7: Linearized Pseudo-First Order Plots

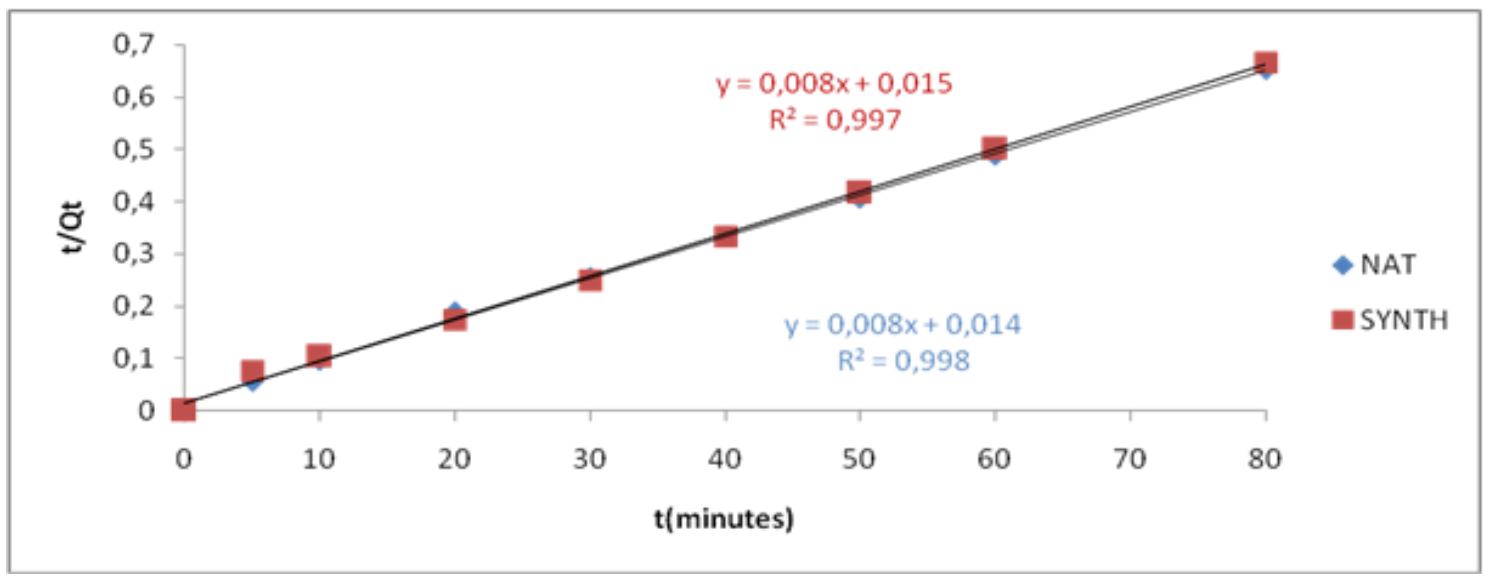

Fig. 8: Linearized Pseudo-Second Order Plots. 


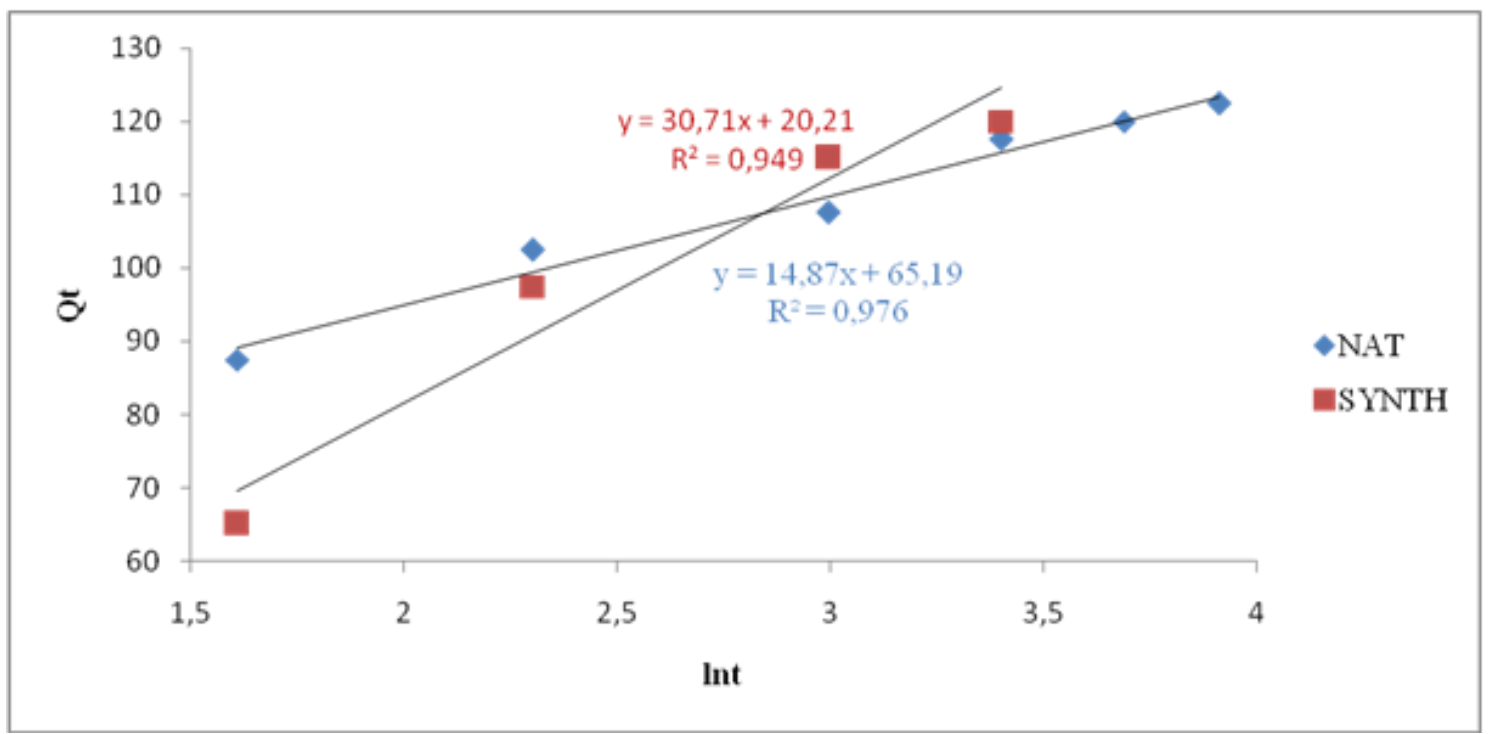

Fig. 9: Linearized ElovichPlots.

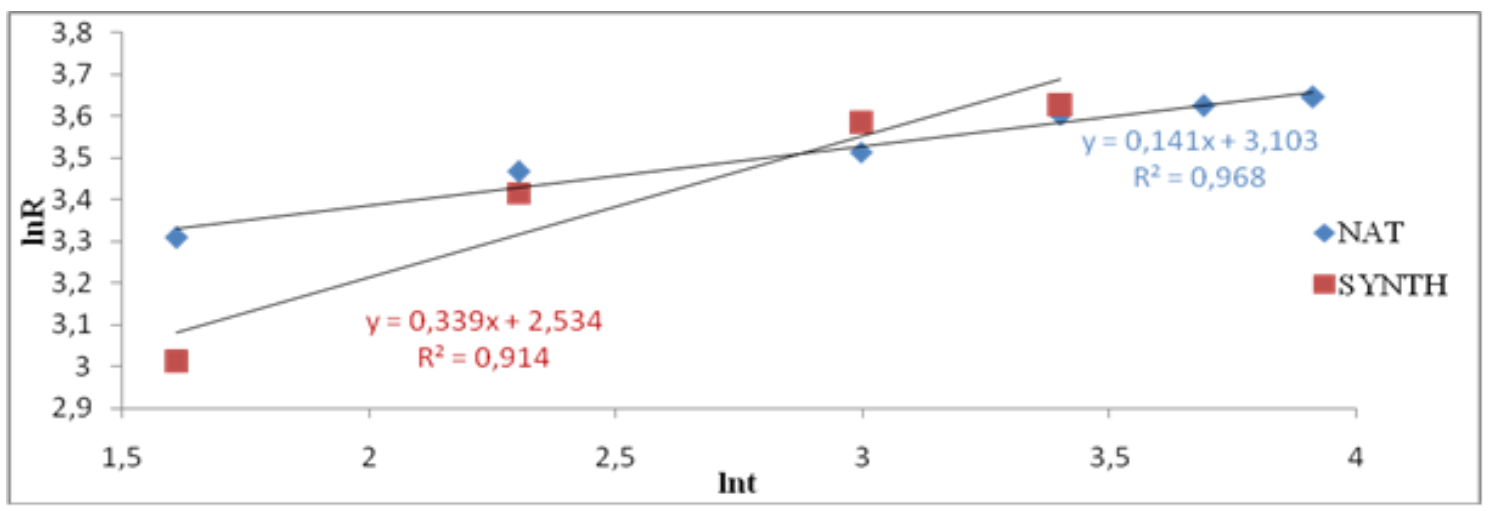

Fig. 10: Linearized Intraparticle Diffusion Plots

These results show that the adsorption of nickel(II) ions on both adsorbents can be well described by pseudo-first order and pseudo-second order kinetic models, with correlation coefficients greater than 0.99. The adsorbed quantities calculated at equilibrium $\left(\mathrm{Q}_{\mathrm{e}}=120 \mathrm{mg} \cdot \mathrm{g}^{-1}\right)$ are close and in accordance with the experimental values. For the NAT, the correlation coefficient is also high for the intraparticle diffusion model, and the intradifusion constant; Kid value is also greater for the NAT. This suggests that the particle diffusion is better for the NAT, and it is probably due to its pore diameter. Hence, for the NAT, both physical and chemical adsorption participates in the overall process which is in agreement with previous work [25], [26]. However, the possibility of chemisorption on the SYNTH surface, the physisorption is also very predominant.

It is also observed that the porosities, the structures and the adsorption mechanisms of the two adsorbents are relatively different. Hence, the magnetic attraction between adsorbate-adsorbent can be explained by the similarity of adsorption capacities. Additionally, if the performance of the NAT is compared to the others adsorbents, it can, then be conclude that the NAT givesgood adsorption results. It is maximum capacity, $Q_{m}$ equals to $250 \mathrm{mg} / \mathrm{g}$ which is larger than the $28,57 \mathrm{mg} / \mathrm{g}$ and $62,89 \mathrm{mg} / \mathrm{g}$ obtained for the removal of $\mathrm{Ni}^{2+}$ ions by Ceralite and Orange peel respectively [27], [5].

Table 3: Kinetics Models Parameters for $\mathrm{Ni}^{2+}$ Ions on the NAT and SYNTH

\begin{tabular}{|c|c|c|c|}
\hline \multirow{2}{*}{\multicolumn{2}{|c|}{$\begin{array}{l}\text { Adsorbents } \\
\mathrm{C}_{\mathrm{o}} \text { of } \mathrm{Ni}(\mathrm{II}) \text { in } \mathrm{mg} / \mathrm{L}\end{array}$}} & NAT & SYNTH \\
\hline & & 1600 & \\
\hline \multirow{3}{*}{ Pseudo first order } & $\mathrm{K}_{1} \cdot \mathrm{min}^{-1}$ & 0.009 & 0.159 \\
\hline & $\mathrm{Q}_{\mathrm{e}}\left(\mathrm{mg} \cdot \mathrm{g}^{-1}\right)$ & 123.47 & 118.63 \\
\hline & $\mathrm{R}^{2}$ & 0.997 & 0.998 \\
\hline \multirow{3}{*}{ Pseudo second order } & $\mathrm{K}_{2}\left(\mathrm{~g} \cdot \mathrm{min}^{-1} \mathrm{mg}^{-1}\right)$ & $4.571 \times 10^{-3}$ & $4.267 \times 10^{-3}$ \\
\hline & $\mathrm{Q}_{\mathrm{e}}\left(\mathrm{mg} \cdot \mathrm{g}^{-1}\right)$ & 125 & 125 \\
\hline & $\mathrm{R}^{2}$ & 0.998 & 0.997 \\
\hline \multirow{3}{*}{ Elovich } & $\mathrm{B}$ & 0.067 & 0.033 \\
\hline & $\mathrm{A}$ & 1177.081 & 59.04 \\
\hline & $\mathrm{R}^{2}$ & 0.976 & 0.949 \\
\hline \multirow{3}{*}{ intraparticle diffusion } & $\mathrm{K}_{\mathrm{id}}$ & 22.265 & 12.60 \\
\hline & $\mathrm{A}$ & 0.141 & 0.339 \\
\hline & $\mathrm{R}^{2}$ & 0.968 & 0.914 \\
\hline
\end{tabular}




\section{Conclusion}

The present investigation reveals that treated iron oxide from the locality of Mbalam in the East region of Cameroon, and the Synthetic iron oxide are efficient materials for the remediation of nikel(II) ions contamination. The adsorption capacities are relatively the same for both adsorbent $\left(\mathrm{Q}_{\mathrm{m}}=250 \mathrm{mg} \cdot \mathrm{g}^{-1}\right)$. The adsorbate-adsorbent interactions are stronger on the NAT than on the SYNTH. The adsorption kinetics follows the pseudo-first order and pseudo-second order for the two adsorbents. Both physical adsorption and chemical adsorption are involved in the adsorption processes on the NAT and SYNTH. Results showed that the high adsorption capacity of the treated natural iron oxide to remove nickel(II) ions is a model scale for the synthetic iron oxide substitution.

\section{Acknowledgements}

Authors thank all the members of the research group "Adsorption and Surface," of Physical and Theoretical Chemistry Laboratory of the University of Yaoundé I for their remarks and suggestions and also Dr. Isaac NONGWE BEAS, Department of Civil and Chemical Engineering UNISA, RSA for recording the BET and XRD of the adsorbents.

\section{References}

[1] Valasange A.B., Patil V.V., Hinge V.R., More N.V. (2012), Effect of Heavy Metals Toxicity on Germination, Early Seedling Growth \& Tolerance of Maize (zea ways) variety safed Ganga. Golden Research Thoughts, 1(12): 1-4.

[2] Tsabel M., Lopez F., Perez C., Lopez-Delgado A., Alguacil F. (2005), Adsorption of Heavy Metals from Aqueous Solution with By-Products of the Steel making Industry. Journal of Chemical Technology and Biotechnology, 80: 1223-1229. http://dx.doi.org/10.1002/jctb.1305.

[3] Hamidi A.E., Arsalane S., Halim M. (2012), Kinetics Studies of Copper Removal by Brushite Calcium Phosphate: Linear and Non-Linear Regression Comparison. E-journal of Chemistry, 9(3):1532-1542. http://dx.doi.org/10.1155/2012/928073.

[4] Shakya P.R. (2007), Nickel Adsorption by Wild Type and Nickel Resistant Isolate of Chorella SP. Pakistan Journal of Analytical Environment Chemistry, 8: 1-2.

[5] Ferda G., Selen S.D. (2012), Adsorption study on Orange Peel: Removal of Ni (II) Ions from Aqueous Solution. African Journal of Biotechnology 11(5):1250-1258.

[6] Madhavakrishman S., Vasagah K., Rasappan K., Syed S.P.S., Venkatesh R., Pathiabhi S. (2008), RicinusComminus Pericarp Activated Carbon Used As an Adsorbent for the Removal of Ni (II) From Aqueous Solution. E-journal of Chemistry, 5(2): 761-769. http://dx.doi.org/10.1155/2008/272370.

[7] Azizinezhad F., Shabani M. (2012), Investigation of the Surface Adsorption of Cd2+ Ions on Modified Poly Ethylene Terephthalate by the Mixture of Methyl Methacrylate Acrylic Acid Monomers. Research Journal of Pharmaceutical Biological and Chemical Sciences, 3(4): 31.

[8] Singh S., Kumer V.L., Sambi S.S., Sharma S.K. (2008), Adsorption Behavior of Ni(II) Ions from Water on Zeolite: Kinetics and Equilibrium studies. Water Resource Research, 1:1-6.

[9] Barkhordor B., Ghiassedin M. (2004), Comparison of Langmuir and Freundlich Equilibrium in Cr, Cu, Ni Adsorption by Sargassum. Iranian Journal Environment Health Science Engineering, 1(2):58-64.

[10] Onundi Y.B., Mamun A.A., Al Khatib M.F., Ahmed Y.M. (2010), Adsorption of Copper, Nickel and Lead Ions from Synthetic SemiConductor Industrial Waste Water by Palm Shell Activated Carbon. International Journal Environment Science Technology, 7(4):751758.http://dx.doi.org/10.1007/BF03326184.

[11] Kanthimathi G., Kotte E.P., Arasu P., Govindaraj P., Kottaisamy M. (2012), A Comparative Study of the Adsorption Efficiency of the Newly Synthetic Nano Iron Oxide And Commercial Activated Charcoal Towards The Removal Of The Nickel(II)Ions. E-Journal of Chemistry, 9(4): 2384-2393.http://dx.doi.org/10.1155/2012/567428.

[12] NdiNsami J., KetchaMbadcam J. (2013), The Adsorption Efficiency of Chemically Prepared Activated Carbon from Cola Nut Shells by $\mathrm{ZnCl} 2$ on Methylene Blue. Hindawi Publishing Corporation Journal of Chemistry, ID 469170: 7.

[13] Essomba J.S., NdiNsami J., BelibiBelibi P.D.,Tagne G.M., KetchaMbadcam J. (2014), Adsorption of Cadmium(II) Ions from Aqueous Solution onto Kaolinite and Metakaolinite. Pure and Applied Chemical Sciences, 2(1): 11 - 30.

[14] Dina Joh D.D., AbdoulNtieche R., NdiNsami J., KetchaMbadcam J. (2012), Adsorption of Acetic acid onto Activated Carbons obtained from Maize cobs by Chemical Activation with Zinc chloride ( $\mathrm{ZnCl2})$. Research Journal of Chemical Sciences 2(9):42-49.

[15] Tagne G.M., NDI Nsami J., KetchaMbadcam J. (2013), Adsorption of Copper(II) Ions from Aqueous Solution onto Synthetic Goethite and Two Naturally Available Red Soils from Yaoundé -Cameroon. British Biotechnology Journal 3(3): 221235.http://dx.doi.org/10.9734/BBJ/2013/3117.

[16] AnaghoGabche S., TchuifonTchuifon D.R., Ndifor-Angwafor N.G., NdiNsami J., KetchaMbadcam J., Mouminou N. (2013), Nickel Adsorption from Aqueous Solution onto Kaolinite and Metakaolinite: Kinetic and Equilibrium Studies. International Journal of Chemistry; [04] ISSN 2306-6415.

[17] KetchaMbadcam J., AnaghoGabche S., NdiNsami J., Kammegne A.M. (2011), Kinetic and Equilibrium Studies of the Adsorption of Lead(II) Ions from Aqueous Solution onto Two Cameroon Clays: Kaolinite and Smectite. Journal of Environmental Chemistry and Ecotoxicology 3(11): 290-297.

[18] KetchaMbadcam J., Dongmo S., Dingka'aNdangu D. (2012), Kinetic and Thermodynamic Studies of the Adsorption of Nickel(II) ions from Aqueous Solutions by Smectite Clay from Sabga-Cameroon. International Journal of Current Research 4(05):162-167.

[19] Kaur S., Pani S., Kumar R.M. (2013), Adsorption Kinetic For the Removal of Hazardous Dye Congo red by Biowaste Materials as Adsorbents. Hindawi Publishing Cooperation Journal of Chemistry: 12.http://dx.doi.org/10.1155/2013/628582.

[20] Masoomeh E., Mohammad K.A. (2013), Removal of Zinc from Aqueous Solutions by Magnetite Silica Core-Shell nanoparticles. Hindawi Publishing Corporation Journal of Chemistry. ID 787682:10.

[21] Bhaltachouya K., Gupta S.S. (2006), Adsorption of Chromium (VI) From Water by Clays. Indian Engineering Chemical Research, 45: $7232-$ 7240.http://dx.doi.org/10.1021/ie060586j.

[22] Elouear Z., Bouzid J., Boujelben N. (2010), Removal of Nickel and Cadmium by Sewage Sludge Ash: Study in Single and Binary Systems. World Wild Workshop for Young Environmental Scientist. Hal 00521318, p. 1-27.

[23] KetchaMbadcam J., TchatatWouaha G.F., Hambate G.V. (2010), .Adsorption of Ferricyanide on Activated Carbon and $\gamma$-Alumina. E-journal of Chemistry 7(3):721-726.http://dx.doi.org/10.1155/2010/645479. 
[24] Ghosh U.C., Bandyopadhay D., Mandal M. (2006), Hydrous Iron (III)-Tin (IV) Binary Mixed Oxide: Arsenic Adsorption Behavior from Aqueous Solution. Water Quality Research Journal of Canada, 41(2):198-209.

[25] KetchaMbadcam J, Ngomo Manga H., Kouotou D., TchouaNgamou P.H. (2007), Kinetic and Equilibrium Studies of the Adsorption of Nitrate Ions in Aqueous Solutions by Activated Carbons and Zeolite. Research Journal Chemistry and Environment, 11(3), 47.

[26] KetchaMbadcam J., BougoTchamande C. (2010), Removal of Mercury(II) Ions from Aqueous Solutions using Granular Activated Carbon (GAC) and Kaolinite Clay from Mayouom in Cameroon: Kinetic and Equilibrium Studies. Research Journal of Chemistry and Environment, 14 (3):60-66.

[27] Senthil K.S., Ramaskrishman K., Gayathri R. (2010), Removal of Nickel (II) from Aqueous Solution by Ceralite IR 120 Cationic Exchange Resins. Journal of Engineering Science and Technology 5(2): 232-243.

\section{Abbreviations}

D-K-R: Dubinin-Kaganer-Radushkevich

FT-IR: Fourier Transform- Infrared

NAT: Natural iron oxide

SYNTH: Synthetic iron oxide

XRD: X-ray diffraction 